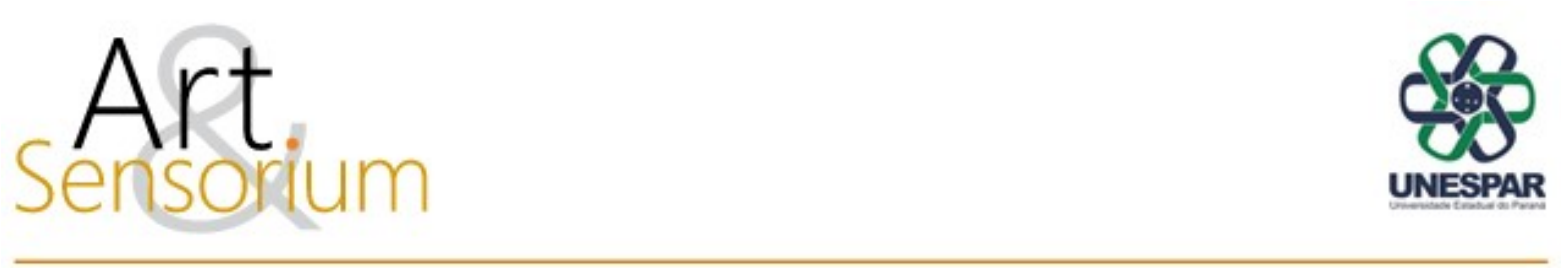

\title{
O HORROR DAS TROUXAS ENSANGUENTADAS, DE ARTUR BARRIO
}

\author{
Giancarlo Backes Couto ${ }^{1}$
}

\begin{abstract}
Resumo: Muitos estudos já se concentraram em teorizar sobre o gênero horror no audiovisual e na literatura, todavia o mesmo não se deu com as artes plásticas. Sendo assim, o principal objetivo deste artigo é defender as Trouxas Ensanguentadas, objetos pertencentes à Situação T/T,1, happening de Artur Barrio, como obra de horror, seja por sua forma e conteúdo. Para defender tal proposição, o texto se apoia principalmente na teoria do horror artístico de Carroll (1999) e nas categorias de desordem, perigo e sujeira, de Douglas (2014).
\end{abstract}

Palavras-Chave: Horror; Trouxas Ensanguentadas; Artur Barrio; Ditadura Brasileira.

\section{THE HORROR OF ARTUR BARRIO'S BLOODIED BODY BAGS}

Abstract: Multiple studies have attempted to provide theories regarding the horror genre in audiovisual art and literature; however, this has not yet been attempted with visual art. As such, the main purpose of this article is to defend the Bloodied Body Bags, objects belonging to Situation $\mathrm{T} / \mathrm{T}, 1$, a happening by Artur Barrio, as a work of horror, whether due to its form or due to its content. In order to ground said assertion, the texts is mostly based on the theory of artistic horror as espoused by Carroll (1999) and in the categories of disorder, danger and dirt established by Douglas (2014).

Keywords: Horror; Bloodied Body Bags; Artur Barrio; Brazilian Dictatorship.

\section{EL HORROR DE LOS PAQUETES ENSANGRENTADOS, DE ARTUR BARRIO}

Resumen: Muchos estudios ya se han centrado en teorizar sobre el género de horror en el audiovisual y la literatura, sin embargo, no sucedió lo mismo con las artes visuales. Por lo tanto, el objetivo principal de este artículo es defender a los Paquetes ensangrentados, objetos pertenecientes a la Situación T / T, 1, happening de Artur Barrio, como una obra de horror, ya sea por su forma y contenido. Para defender esta proposición, el texto se basa principalmente en la teoría del horror artístico de Carroll (1999) y en las categorías de desorden, peligro y suciedad, de Douglas (2014).

Palabras Clave: Horror; Paquetes Ensangrentados; Artur Barrio; Dictadura Brasileña.

\footnotetext{
${ }^{1}$ Mestre em Comunicação Social pela Pontifícia Universidade Católica do Rio Grande do Sul (PUCRS), na linha de pesquisa Cultura e Tecnologias das imagens e dos imaginários. Orcid: https://orcid.org/0000-0001-9757-522X. E-mail: giancarlobcouto@gmail.com.
} 


\section{Introdução}

$\mathrm{Na}$ introdução de seu livro sobre o que ele mesmo denomina como Horror artístico, Nöel Carroll (1999) retraça uma breve história do gênero horror nas artes. Excetuando-se a passagem em que apenas cita os nomes de Francis Bacon, Hans Rudolf Giger e Sibylle Ruppert, o autor não dá muita atenção às artes plásticas no panorama do horror. Seu foco, como é comum a outros teóricos, se centra na literatura e cinema, visto que, de fato, foram os meios artísticos pelos quais o gênero do horror se consolidou e atingiu o maior número de pessoas. O primeiro propósito deste trabalho é, então, a partir de uma análise das Trouxas Ensanguentadas, de Artur Barrio, demonstrar que o gênero do horror está presente também nas artes plásticas, seja pela forma ou conteúdo.

Carroll (1999) estabelece dois norteadores para diferenciar o que ele chama de horror artístico do horror natural. Grosso modo, enquanto o primeiro se liga às obras de arte em geral, abrangendo literatura, cinema, teatro, balé, pintura etc; o segundo é o horror do cotidiano, ligado à emoção que sentimos relacionada a determinado acontecimento. Como fica claro, o horror natural incide no artístico, todavia, essa categorização é importante num primeiro momento para cercar os objetos de estudo. Carroll, talvez por sua tradição analítica anglo-saxã, se sinta, em muitos momentos, impelido a categorizar em demasia seus objetos, o que, a meu ver, fecha demais as possibilidades de leitura. Procurarei então abrir mais seus conceitos, justamente por crer que essa incidência do horror natural é um ponto importante na constituição do horror artístico e é impossível separá-los tão pragmaticamente.

Justamente por essa relação do horror natural com o horror artístico é que podemos pensar os motivos do sucesso do gênero. Quando Benjamin (2012) descreve o quadro Angelus Novus, de Paul Klee, ele destaca justamente o aspecto horrorizado da face do anjo que é impelido ao futuro, mas que tenta desesperadamente se voltar ao passado, para tentar despertar os mortos e reconstruir as ruínas que se amontoam pela história. O horror está entranhado em nossa história, principalmente em momentos de barbárie, que foram tantos no século XX. Não por acaso, como o próprio Carroll (1999) aponta, foi depois das imagens da Guerra do Vietnã que o gênero explodiu para as massas, deixando seu lugar de entretenimento de nicho. É nesse sentido que pretendo relacionar a obra de Artur Barrio, suas Trouxas Ensanguentadas, espalhadas pelos córregos e esgotos da cidade, que atraíram a atenção da população e autoridades, como a polícia e os bombeiros. Como pretendo mostrar também, além dessa dimensão de relação entre horror no cotidiano e horror artístico, mediada pelos afetos, a obra de Barrio também contempla, mesmo que indiretamente, a categorização de Carroll (1999) para ser inserida no gênero, pois possui um monstro e se relaciona com as categorias de desordem, perigo e sujeira (DOUGLAS, 2014). Nas duas primeiras partes do texto então estabelecerei o aporte teórico de onde parto, para, em seguida, analisar e fazer as relações com as Trouxas Ensanguentadas, de Artur Barrio.

\section{Horror natural vs. Horror artístico}

Para Carroll (1999), o horror artístico é marcado principalmente por dois pontos, o primeiro relacionado a recepção do espectador e o segundo a presença de um monstro que desafia os princípios ontológicos e sociais no conteúdo da obra. Os afetos, então, constituem parte importante no gênero do horror. O nome do gênero por si só já advém desse sentimento que causa no espectador. "A palavra 'horror' deriva do latim 'horrere' - ficar em pé (com o cabelo em pé) ou eriçar - e do francês 'orror' - eriçar ou arrepiar" (CARROLL, 1999, p. 41). O autor classifica então como horror primeiramente as obras artísticas e narrativas que causem esse afeto no espectador ou que pelo menos tenham esse intuito.

Esse tipo de explicação pode até servir para exemplares do gênero, todavia, é um dado muito subjetivo, que, me parece, se perdeu com o tempo. Ele se aplica muito mais facilmente a outros períodos históricos, com uma presença mais forte do sobrenatural no imaginário das pessoas. Sobre 
isso, Laura Cánepa (2008, p. 16) define bem: “modernamente, observa-se que muitas histórias de horror parecem mais ligadas ao gênero Estranho - isto é, tratam de situações de medo e abjeção protagonizadas por indivíduos com características monstruosas, mas não sobrenaturais". O que pretendo esclarecer aqui, de antemão, é que o sobrenatural não é necessariamente um dado sempre presente no horror.

Isso nos leva então ao outro dado que Carroll (1999) aponta como fundamental para o horror artístico, a presença de um monstro que desafie as convenções de ordem. Esse ponto é importante e se relaciona também com o estado fisiológico do horror justamente porque ele se relaciona com o espectador e com outros personagens da narrativa. Como o autor destaca, monstros são comuns em outras narrativas, como a fantasia, por exemplo. A diferença para o horror é a relação dos monstros com os outros personagens. Carroll (1999, p. 31) ressalta: "Nas obras de horror, os humanos encaram os monstros que encontram como anormais, como perturbação da ordem natural". Ou seja, mesmo causando perigo em outras narrativas (pensemos aqui em Star Wars, por exemplo, um universo cheio de monstros que causam perigo, mas não necessariamente colocam a série no gênero do horror), esses monstros são comuns aquele universo. No horror não, eles precisam funcionar como uma quebra da ordem ontológica e social.

A reação afetiva do personagem ao monstruoso nas histórias de horror não é simplesmente uma questão de medo, ou seja, de ficar aterrorizado por algo que ameaça ser perigoso. Pelo contrário, a ameaça mistura-se à repugnância, à náusea e à repulsa. E isso corresponde também à tendência que os romances e as histórias de horror têm de descrever os monstros com termos relativos a imundície, degeneração, deterioração, lodo etc., associando-os a essas características. Ou seja, o monstro na ficção de horror não só é letal como também — e isso é da maior importância repugnante. [...] No contexto da narrativa de horror, os monstros são identificados como impuros e imundos. São coisas pútridas ou em desintegração, ou vêm de lugares lamacentos, ou são feitos de carne morta ou podre, ou de resíduo químico, ou estão associados com animais nocivos, doenças ou coisas rastejantes. Não só são muito perigosos como também provocam arrepios. Os personagens vêem não só com medo, mas também com nojo, com um misto de terror e repulsa (CARROLL, 1999, p. 39).

Logo, os monstros precisam ser ameaçadores e impuros. Essa relação da desordem e impureza é melhor aprofundada pela antropóloga Mary Douglas (2014), a quem irei aludir posteriormente, pois, a meu ver, suas categorias se aplicam muito bem às obras de Barrio. No momento, gostaria, porém, de abrir a concepção de Carroll (1999), pois ela parece por demasiado fechada, já que o autor se preocupa em diferenciar o horror artístico do horror natural, o horror do cotidiano ou aquela repulsa causada em momentos nos quais nos deparamos com atrocidades, extrema violência ou qualquer coisa que nos cause repulsa e/ou medo.

A preocupação de Carroll (1999) em fazer essas separações é importante para melhor fazer com que seus leitores o compreendam, todavia, ela me parece estabelecer uma cisão entre arte e mundo, quando na verdade a própria etimologia da palavra horror só é possível por uma ligação do espectador com a obra. Ou seja, só sentimos horror a uma obra artística pois ela representa e tem relação com o nosso estado no mundo. 
O próprio monstro, como demonstra Foucault (2001) é derivado de uma noção nada sobrenatural. Em seu curso no Collège de France, dado entre 1974 e 1975, o autor mostra que, para chegar ao que hoje vemos como o sujeito anormal ${ }^{2}$ passamos pelo monstro, que ele define do seguinte modo:

\begin{abstract}
O contexto de referência do monstro humano é a lei, é claro. A noção de monstro é essencialmente uma noção jurídica - jurídica, claro, no sentido lato do termo, pois o que define o monstro é o fato de que ele constitui, em sua existência mesma e em sua forma, não apenas uma violação das leis da sociedade, mas uma violação das leis da natureza. Ele é, num registro duplo, infração às leis em sua existência mesma. O campo do aparecimento do monstro é, portanto, um domínio que podemos dizer "jurídico-biológico". Por outro lado, nesse espaço, o monstro aparece como um fenômeno ao mesmo tempo extremo e extremamente raro. Ele é o limite, o ponto de inflexão da lei e é, ao mesmo tempo, a exceção que só se encontra em casos extremos, precisamente. Digamos que o monstro é o que combina o impossível com o proibido (FOUCAULT, 2001, p. 69-70).
\end{abstract}

Desde a antiguidade romana já se estabelecia uma diferença clara entre o defeituoso, num sentido médico, de doença, e o monstruoso, nesse sentido jurídico. É na Idade Média, porém, que esse monstro já se torna mais próximo do mencionado por Carroll (1999). Ele é percebido num sentido de mistura, seja entre reinos (animal e humano, como o homem com cabeça de boi); mistura de espécies (porco com cabeça de carneiro); mistura de corpos (homem com duas cabeças); mistura de sexos (hermafrodita). Esse monstro é uma afronta às leis divinas, mas também às civis "só há monstruosidade onde a desordem da lei natural vem tocar, abalar, inquietar o direito, seja o direito civil, o direito canônico ou o direito religioso" (FOUCAULT, 2001, p. 79). É por isso que a monstruosidade se distingue da enfermidade, pois ela solapa as leis naturais e jurídicas. A enfermidade também abala a ordem natural, porém não é uma afronta à sociedade ou a religião.

A partir do século XVIII Foucault (2001) nota o estabelecimento das noções de monstruosidade muito mais presentes no nosso cotidiano, como o Estranho apontado por Cánepa (2008). O foco deixa de ser a desordem natural, que ainda tem a sua importância, é verdade, mas passa a se relacionar com a desordem moral. É a monstruosidade do comportamento. É a partir desse momento que a monstruosidade se torna criminosa, explodindo sob a forma jurídica. Antes, a monstruosidade era uma característica do criminoso, agora ela é uma categoria em si. Surge Sade, a figura do criminoso monstruoso, assim como também os monstros morais da literatura gótica.

Essas concepções podem ser vistas muito bem no campo político. O exemplo de Foucault (2001), nesse sentido, é o da França, em que Maria Antonieta era retratada pelos revolucionários jacobinos como uma monstra que sugava o sangue dos súditos, uma vampira. Do mesmo modo, essa monstruosidade se confundia com o campo moral, pois ela era acusada de ter relações incestuosas e homossexuais. A monarquia não agia de modo diferente. Se espalharam relatos de que os revolucionários estupravam e até canibalizavam membros da nobreza. É durante esse processo que surge também a literatura de horror preocupada com esses mesmos temas. O tirano e o homem do povo sanguinolento se materializam sob duas formas:

De um lado, temos o monstro por abuso de poder: é o príncipe, é o senhor, é o mau padre, é o monge culpado. Depois, temos também, nessa mesma literatura de terror,

\footnotetext{
${ }^{2} \mathrm{O}$ curso de Foucault é focado nos anormais, mas para chegar neles o autor traça a genealogia do monstro, excerto que exploro aqui. A definição de Anormal não nos interessa tanto aqui, apesar de, como demonstra Foucault, ela se dar a partir do monstro.
}

R. Inter. Interdisc. Art\&Sensorium, Curitiba, v.7, n.2, p. 001 - 014 Jul.- Dez. 2020 
o monstro de baixo, o monstro que volta à natureza selvagem, o bandido, o homem das florestas, o bruto com seu instante ilimitado (FOUCAULT, 2001, p. 124-125).

Como fica claro, o monstro tem, antes de sua dimensão sobrenatural, uma dimensão social. É por isso que determinados ciclos de horror são tão caros a determinadas épocas. Além dos exemplos citados por Foucault (2001), eu poderia ressaltar aqui as pinturas apocalípticas da Idade Moderna, quando se acreditava na iminência do Juízo Final, o expressionismo do cinema alemão após a Primeira Guerra Mundial, o ciclo de filmes de horror nos Estados Unidos após a Guerra do Vietnã, o sucesso dos filmes de José Mojica Marins durante a Ditadura Civil-Militar no Brasil e o ressurgimento do gênero com o chamado "pós-horror", após a crise econômica mundial de 2008.

\section{O horror na forma}

Tanto a questão da repulsa e do medo como um afeto causado pelo horror quanto pelo monstro em si são dados que se relacionam diretamente com a forma. Isso é provado por Douglas (2014) que, em sua investigação sobre as origens dos nossos conceitos de pureza e impureza, encontrou as respostas na ordem e na desordem. Em seu estudo, utilizado por Carroll (1999) para estabelecer as categorias do monstro, a autora propõe que a desordem é o reduto do impuro, enquanto a ordem se relaciona diretamente com a pureza. A ordem só pode ser produzida através de uma sistematização, que por sua vez produz sobras, restos... As anomalias que confrontam a nossa percepção do mundo. Como exemplo de impureza, Douglas (2014) analisa as abominações do Levítico, as quais consistem em animais impuros que devem ser evitados na dieta. Estes animais são classificados de acordo com sua inserção em categorias e não, como pode parecer num primeiro momento, pelo meio em que vivem ou do que se alimentam.

No Antigo Testamento, mal e bem perpassam pelas noções de benção divina. A benção é fonte das coisas boas e a falta de benção é fonte das ruins. "O trabalho de Deus através da benção é, essencialmente, criar a ordem pela qual os negócios dos homens prosperam. [...] Onde a benção é retirada e a força da maldição desencadeada, há esterilidade, peste, desordem." (DOUGLAS, 2014 p. 66). Sendo assim, se Deus utiliza a benção para criar ordem, o que está fora dela não foi abençoado, se tornando, consequentemente, perigoso e impuro.

Todas estas prescrições ${ }^{3}$ são prefaciadas por um mandamento geral: "Vós sereis santos, porque eu sou santo". Podemos concluir que a santidade é exemplificada pela integridade. A santidade requer que os indivíduos se conformem à classe à qual pertencem. E a santidade requer que diferentes classes de coisas não se confundam.

Outro conjunto de preceitos aperfeiçoa esta ideia. A santidade significa manter distintas as categorias de criação. Ela, portanto, envolve definição correta, discriminação e ordem. Sob este título, todas as regras de moralidade sexual exemplificam o santo (DOUGLAS, 2014, p. 70).

Como a santidade está ligada a unidade do homem com o santo, as regras dietéticas descritas no Levítico são exemplificações dessa busca pela santidade integrada. Essas regras funcionam como símbolos para que o homem se lembre constantemente da necessidade de estar em unidade com Deus. Animais providos por Deus e criados pelos israelitas, como o gado e o carneiro, por exemplo, eram considerados puros. Eles se inserem nessa categoria por estar dentro da ordem divina.

${ }^{3}$ Aqui Douglas (2014) se refere a proibições ligadas à moral.

R. Inter. Interdisc. Art\&Sensorium, Curitiba, v.7, n.2, p. 001 - 014 Jul.- Dez. 2020 
O mais interessante, todavia, é o que toca aos animais impuros e proibidos. Essa separação se dava por duas características ligadas ao gado e ao carneiro, o ruminar e o casco fendido. É em relação das dissonâncias dessas características que alguns animais são proibidos. A lebre, por exemplo, apesar de constantemente ranger de dentes, ruminando, era proibida, pois não tinha o casco fendido. O porco tem o casco fendido, porém não rumina, logo seu consumo é proibido. Como se nota, ele não é considerado impuro por viver na lama ou se rolar no seu próprio esterco, mas sim por sua afronta a categorias.

No que toca aos animais selvagens, os critérios de impureza seguem os de classificação e ordem:

\begin{abstract}
Para atingir este esquema precisamos retornar ao Gênesis e à criação. Aqui se desdobra uma classificação tripartida, dividida entre terra, as águas e o firmamento. O Levítico toma este esquema e atribui para cada elemento o tipo de vida apropriado. No firmamento, aves de duas pernas voam com asas. Na água, peixes com escamas nadam com nadadeiras. Na terra, animais de quatro pernas pulam, saltam ou andam. Qualquer classe de criaturas que não esteja equipada para o tipo correto de locomoção no seu elemento é contrária à santidade. O contato com ela desqualifica uma pessoa a aproximar-se do Templo. Portanto, qualquer coisa da água que não tenha nadadeiras e escamas é impura $(11,10-12)$. Não é dito a respeito dos hábitos predatórios ou de alimentação de carniça. O único teste seguro de limpeza para um peixe são suas escamas e a sua propulsão por meio de nadadeiras (DOUGLAS, 2014, p. 72).
\end{abstract}

Como se percebe, a impureza desses animais se liga a desordem de suas categorias, ao erro. Logo, eles são anomalias de formas, estando fora de um padrão estabelecido no Gênesis

A impureza está no erro, na ambiguidade e, principalmente, no deslocamento. Enguias são exemplos de animais que vivem nas águas, mas não são peixes, por isso são impuros. Do mesmo modo, alguns répteis andam na terra, mas não são quadrúpedes e insetos voam, mas não são aves.

Apesar de parecer distante, convém demarcar que isso não se aplica apenas às questões dietéticas de povos antigos. Stuart Clark (2006) destaca que as bruxas do século XVI e XVII eram relacionadas com a desordem, irracionalidade e tom carnavalesco ${ }^{4}$. Por sua vez, eram seres impuros e seus malefícios geralmente giravam em torno da sujeira, doença e infecciosidade (tanto física quanto da alma). Como Douglas (2014) conclui, o ambiente social é dividido por linhas e, quando essas percepções se confundem, a poluição aparece como um denominador a fim de marcar essas linhas divisórias. O perigo está no deslocamento e também na intrusão. “Joana D'arc pode ser tomada como um esplêndido protótipo dessas: uma camponesa na corte, uma mulher no exército, uma intrusa no conselho de guerra; a acusação de que era uma bruxa põe-na inteiramente nessa categoria" (DOUGLAS, 2014, p. 127).

Como podemos perceber, a desordem e impureza não são características do monstro à toa, elas vêm de séculos como representações do homem. Isso nos permite pensar o horror tanto no conteúdo como em sua forma. Como Douglas sugere: "Onde há sujeira, há sistema. Sujeira é um subproduto de uma ordenação e classificação sistemática de coisas, na medida em que a ordem implique rejeitar elementos inapropriados" (DOUGLAS, 2014, p. 50). E isso, além de fornecer a constituição do monstro para Carroll (1999), pode nos ajudar aqui a pensar a guinada da arte contemporânea, que passou a utilizar o detrito, o lixo, o sangue e todo tipo de substância que se convencionou chamar de "resto". As Trouxas Ensanguentadas, não seriam claramente uma junção de todo tipo de resto abjeto que Artur Barrio recolhia por aí? A questão aqui é que a sujeira não é sujeira em si, mas surge apenas

${ }^{4} \mathrm{O}$ carnaval é claramente uma subversão momentânea da ordem.

R. Inter. Interdisc. Art\&Sensorium, Curitiba, v.7, n.2, p. 001 - 014 Jul.- Dez. 2020 
num deslocamento da ordem. Talvez essa seja uma das chaves para se pensar as Trouxas Ensanguentadas como objetos de horror.

\section{Situações-Trouxa}

Na tarde do dia 20 de abril de 1970 uma multidão se aglomerou em volta do córrego Ribeirão Arrudas, no Parque Municipal de Belo Horizonte. Estavam ali catorze corpos ensacados e desovados naquele misto de arroio e esgoto. Muito provavelmente eram obra do Esquadrão da Morte, que agia no mundo real e no imaginário de todos, incentivados ainda mais pelo AI-5.

Imagino que isso tenha sido a primeira coisa que veio a cabeça da maioria dos transeuntes que se detiveram diante do Ribeirão Arrudas para observar aquelas trouxas de sangue. Essa relação, além de facilmente dedutiva, se confirma pela polícia e corpo de bombeiros logo acionados para ir ao local averiguar a situação. Acontece que essa obra não era do Esquadrão da Morte, mas sim de Artur Barrio, um radical artista luso-brasileiro, que entrava para a história da arte brasileira com suas Trouxas Ensanguentadas.

Essas catorze trouxas faziam parte da obra Situação T/T,1, que ainda continha outras fases. Convidado por seu amigo e crítico de arte Frederico Morais, forte defensor da arte de vanguarda brasileira, para participar da mostra Do Corpo à Terra, Barrio preparou esse trabalho em três fases, em três dias diferentes. Na noite de 19 de abril se deu a primeira fase, batizada de 14 movimentos ou Preparação das T. E., nela Barrio produziu em tons ritualísticos as catorze Trouxas. Essa elaboração foi toda registrada pelas lentes de seu amigo e fotógrafo César Carneiro. A preparação consistia no artista estender os panos no chão e sobre eles jogar carne, sangue, ossos, barro, espuma de borracha e outros tipos de detrito. Após isso, Barrio enrolou os panos com os objetos dentro e compôs suas trouxas, amarrando-as com cordas. A segunda fase da obra, no dia seguinte, compreendeu dois movimentos. O primeiro de jogar as Trouxas no Ribeirão Arrudas e o segundo de esperar e observar a reação das pessoas. Como essa é a fase que me interessa propriamente, a descreverei mais detalhadamente na sequência. Para fechar a Situação T/T,1, no dia 21 de abril Barrio se dirigiu novamente ao Ribeirão Arrudas, onde foi fotografado por César Carneiro enquanto jogava rolos de papel higiênico ao vento. Essa parte evocava diretamente outra obra sua, $P \ldots H \ldots$, feita no ano anterior, que consistia no mesmo modus operandi (FREITAS, 2013).

Esse não foi o primeiro dos happenings envolvendo as Trouxas Ensanguentadas. Alguns meses antes, Barrio as havia composto para o Salão da Bússola. Intitulada ORHHHHHHH ... ou ... 5.000 ... T.E... em .... N.Y... City......, a ação ocorreu entre novembro e dezembro de 1969. Ali, depois de um mês de exposição de duas trouxas, Barrio se dirigiu ao Museu de Arte Moderna, onde produziu um happening com os objetos (FREITAS, 2013). Essa ação do Salão da Bússola não me interessa neste texto, pois vai em outro sentido e não se encaixa como uma obra do gênero horror. Curiosamente, $o$ contexto aqui remete a outro tipo de leitura das Trouxas. Expostas em um museu, elas dialogam muito mais com o papel da institucionalização e fetichismo da arte em si. Por outro lado, ao ser deslocadas para o ambiente urbano, as Trouxas prontamente adquirem outro significado, "o sentido e a força das trouxas ensanguentadas confundem-se com a tensão criada pela conjuntura que as originou" (FREIRE, 2005, p. 149). As trouxas se tornam objetos de horror e é a isso que irei me ater nos próximos parágrafos. Para provar, por assim dizer, que a obra de Barrio pode ser encaixada nesse gênero, irei aludir a três pontos dela: sua forma, sua característica de assalto ao espectador e o monstro que elas possuem.

\section{As Trouxas Ensanguentadas como obras de horror}

Dentre os relatos de bruxaria no começo da Idade Moderna, alguns se destacam pela relação entre o abjeto e as mulheres acusadas do pacto com o demônio. "Cravos de ferro, grossos trinchantes ou pontas de varetas nodosas, vidro, osso, cachos de cabelo, maços de linho, cânhamo e pedras, e outros R. Inter. Interdisc. Art\&Sensorium, Curitiba, v.7, n.2, p. 001 - 014 Jul.- Dez. 2020 
tipos de bugigangas de aparência repugnante e odiosa", escreveu o demonólogo Boiastuau (apud CLARK, 2006, p. 475), ao relatar sobre um famoso caso de Constance, no qual uma bruxa teria confessado ter tido relações sexuais com o demônio e em seguida dado a luz a tais objetos. Como Douglas (2014, p. 12) declara de antemão na introdução de seu livro, "a sujeira é, essencialmente, desordem". Retomando uma citação já anterior e a detalhando:

Se pudermos abstrair patogenia e higiene de nossa noção de sujeira, estaremos diante da velha definição de sujeira como um tópico inoportuno. Esta é uma abordagem muito sugestiva. Implica duas condições: um conjunto de relações ordenadas e uma contravenção desta ordem. Sujeira, então, não é nunca um acontecimento único, isolado. Onde há sujeira, há sistema. Sujeira é um subproduto de uma ordenação e classificação sistemática de coisas, na medida em que a ordem implique rejeitar elementos inapropriados (DOUGLAS, 2014, p. 50).

Em seguida a autora dá vários exemplos pertinentes, os sapatos que não são sujos em si, mas se tornam sujos ao serem colocados sobre a mesa de jantar, a comida que não é suja, mas se torna sujeira se for deixada salpicada na roupa, utensílios de cozinha no quarto, roupas espalhadas pela casa etc. Como fica claro, a nossa relação com o lixo não é algo estritamente problemático dentro de uma sociedade de consumo, mas uma questão que já vem desde os tempos mais primitivos, por assim dizer.

A relação de Barrio com o lixo não era nova nas Trouxas Ensanguentadas. Indiretamente a obra $P$... $H$... já dialoga com questões escatológicas e efêmeras, a "arte produzida no banheiro", como ele gostava de se referir. De modo mais direto, Barrio produziu, em 1970, a Situação... Defl ... + S $+\ldots$ Ruas... Abril..., ação em que espalhou 500 sacos de plástico contendo detritos e objetos pela cidade do Rio de Janeiro. "O lixo, recolhido e embalado pelo artista, simplesmente retornava à dispersão social da vida urbana, ao trânsito efêmero das cidades, numa operação de ressignificação de espaços 'invisíveis', como os são os espaços de indigência ou da abjeção" (FREITAS, 2013, p. 130). Barrio dialogava aqui com um ponto claro de Douglas (2014), o lixo como uma noção de espaço. As Trouxas, todavia, são representações bem mais fortes, nesse sentido:

Dejetos, detritos. Aquilo que simplesmente resta e, portanto, não compõe o todo como discurso. As sobras, enfim, do trabalho como atividade biológica e social, como operação transformadora, como movimento e decomposição dos corpos, organismos e sociedades. Carne e sangue, resquícios da vida, da indústria, jornais e espumas, papéis velhos, sacos e panos - o lixo, afinal, a sujeira do mundo como matéria-prima, tudo à disposição do artista. Embale, ensaque tudo, amarre com cordas, perfure e faça sangrar, deixe entrever a matéria informe. Exponha a matéria ao mundo e abandone à sorte, às reações humanas, à deterioração da natureza. Condição obrigatória: As Trouxas Ensanguentadas, esses sacos de abjeções, só funcionam no diálogo direto com o entorno imprevisível do tempo e da história. São, numa palavra, o avesso de Matisse: desconfortáveis (FREITAS, 2013, p. 115).

Essa citação bem que poderia estar presente no livro de Douglas (2014), ela provavelmente veria em Barrio um grande exemplo de sua teoria. Mas, fora isso, aqui, as Trouxas Ensanguentadas parecem dialogar diretamente com aquilo que Gagnebin (2000) chamou de sublime após Auschwitz. Se outrora o sublime era o grandioso e belo, o inexplicável que trazia temor e ao mesmo tempo admiração (SCHILLER, 2011), agora é a irrepresentabilidade do mal, da vergonha e da culpa. "Um 'sublime' de lama e de cuspe, um sublime por baixo, sem enlevo nem gozo" (GAGNEBIN, 2000, p. 108). Foi essa a força das Trouxas que emergiram do córrego Ribeirão Arrudas naquele 20 de abril de 1970. 
Elas emergiram dos esgotos, das águas sujas para se escancarar diante dos olhos dos transeuntes. As Trouxas representavam o irrepresentável, davam forma aos corpos desaparecidos na ditadura, aos corpos disformes descartados no lixo. Compostas tanto por lixo, como jornais, espuma, cordas etc, quanto por restos de carne e sangue, as Trouxas misturavam todo tipo de material biológico e físico. Eram reminiscências daquilo que perambulava o imaginário das pessoas naquele período, mas que só tomou uma forma verdadeira na imagem de Vladimir Herzog enforcado, cinco anos depois.

Freitas destaca que os objetos-trouxa são como "a fusão entre o carnal e o ideal" (FREITAS, 2013, p. 123), ou seja, o trabalho de Barrio aqui é o de organizar, dar forma. Barrio não produz mais lixo, ele o organiza, reúne os detritos, os restos, as reminiscências e dá forma a elas. O artista cria corpo, sistematiza toscamente o impuro, as anomalias criadas por um sistema repressivo. O horror abstrato e irrepresentável toma forma, como na representação clássica de um fantasma que é coberto por um pano. O que dá medo efetivamente não é o pano que se apresenta diante de nós, que advém da nossa realidade, mas sim o etéreo que ele enforma, aquilo que pertence ao além, ao que desconhecemos e não queremos ver. Do mesmo modo que Benjamin dizia que todo monumento era um monumento a barbárie, toda Trouxa desvela a barbárie anterior a ela. Barrio então deu forma e ordenou as anomalias, a desordem. Colocando em prática critérios do sublime asqueroso (GAGNEBIN, 2000) e da repugnância dos restos (DOUGLAS, 2014), criou uma obra que já em sua forma expressa o horror do irrepresentável.

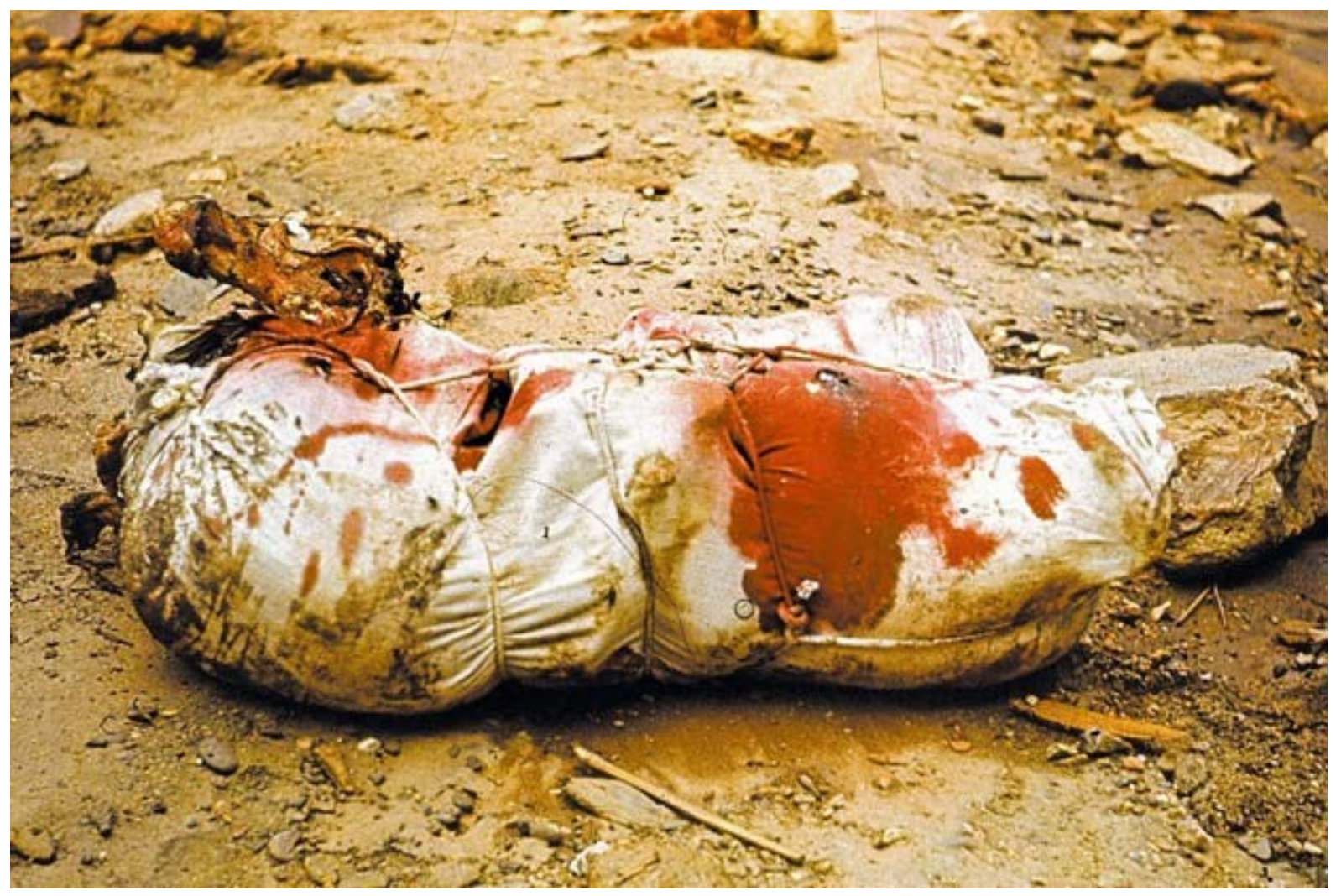

Figura 1 - Uma das catorze Trouxas despejadas no Ribeirão Arrudas. Foto: César Carneiro

Por outro lado, justamente o que difere essa Situação T/T,1 daquela produzida meses antes no Rio de Janeiro é o seu contexto. E aqui me refiro ao seu poder de assalto ao espectador. Como Carroll (1999) aponta, uma das bases do gênero horror é a relação de afetos que ele causa no espectador ou naqueles envolvidos na narrativa. Se a questão fisiológica está presente nas Trouxas através de seu composto e de sua forma, ela também se dá no diálogo com o espectador, efetivamente seu poder de choque pela situação temporal e espacial na qual está inserida. 
Num contexto de ditadura e suspensão da participação democrática, não só Barrio, como talvez todos os artistas da vanguarda brasileira criam numa arte que priorizasse a participação dos espectadores, em vez de sua simples observação desinteressada dos museus e das galerias. Os Parangolés de Hélio Oiticica, as Urnas Quentes de Antônio Manuel, o Projeto Coca-Cola de Cildo Meireles, todos eles buscavam essa interação direta com o público e a saída da arte de seus espaços institucionalizados (CALIRMAN, 2013; FREITAS, 2013.). Barrio não foi diferente e provavelmente foi o mais radical deles. Nesse intuito do choque, o artista retirou sua arte do museu, a dessacralizou e a jogou no esgoto das ruas. Se desfazendo de qualquer tipo de aura (as trouxas eram feitas com o propósito de ser descartadas e os únicos registros que se tem delas são as imagens dos happenings e um protótipo de trouxa $^{5}$ ), Barrio produziu o horror através do choque e do suspense, questões tão caras ao gênero do horror.

\begin{abstract}
Largando seus objetos-trouxa, já em si mesmos formalmente violentos, no curso marginal e tortuoso do esgoto urbano, o artista simulou, no plano estrutural, o destino, no auge da ditadura militar, dos muitos sujeitos desaparecidos e evocou no imaginário coletivo os sinais da violência policial. Mais do que isso, ele criou um fato social, um acontecimento político que deu, ao final das contas, inusitada visibilidade à prática naturalmente invisível do terror. Barrio, numa palavra, trouxe o medo (FREITAS, 2013, p. 162).
\end{abstract}

Segundo Barrio, cerca de cinco mil pessoas chegaram a participar do happening no Parque Municipal de Belo Horizonte. O número não importa tanto, na verdade, mas as imagens da época deixam claro a relação de curiosidade mórbida dos indivíduos interpelados pelas trouxas. Não por acaso, autoridades foram chamadas ao local para averiguar o ocorrido. Tal situação revela que o artista atingiu seu intuito e, como Freitas (2013) acentua, desvelou a prática do crime de Estado. Os relatos da época geralmente acabam sendo nesse sentido, se evoca a participação do Esquadrão da Morte e se remete diretamente às vítimas da ditadura. Retirar as obras dos círculos que elas comumente estão se mostrou aqui uma jogada inventiva justamente por deslocá-las com um truque para diante dos homens comuns, dos transeuntes alheios à arte, mas cientes do terror do Estado. Aqui se nega a tautologia da galeria e se abrem os significados criativos das ruas. Como poderia apontar DidiHuberman (2010), as imagens praticamente olham e falam com quem as observa.

\footnotetext{
5 "O trabalho não é recuperado, pois foi criado para ser abandonado e seguir sua trajetória de envolvimento psicológico" (BARRIO apud FREITAS, 2013, p.159).
} 


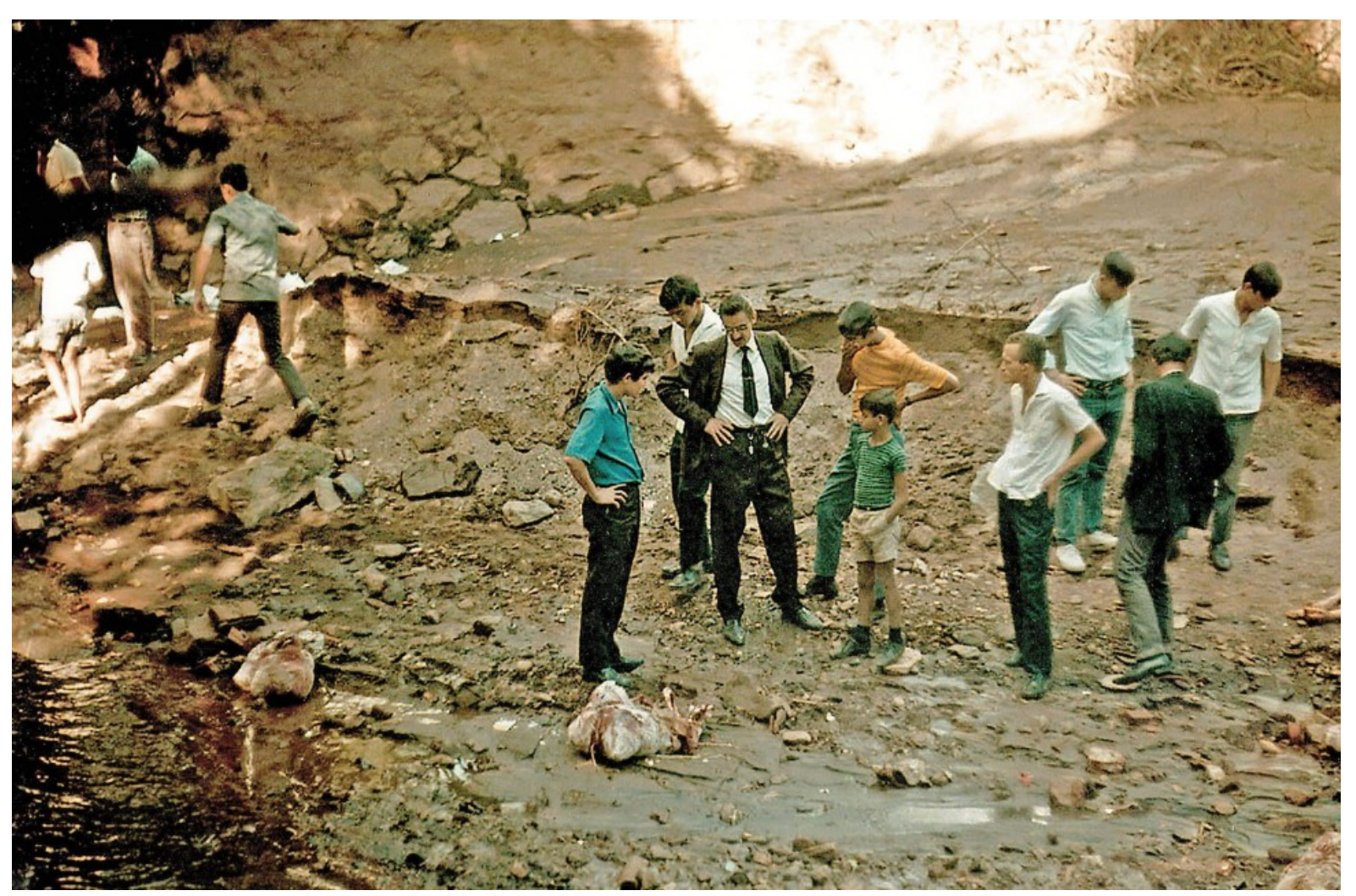

Figura 2 - Transeuntes observando as Trouxas. Foto: César Carneiro

Durante a Ditadura brasileira provavelmente o maior vilão/monstro do cinema foi o personagem Zé do Caixão. Sem dúvidas um personagem sádico como esse chamava a atenção e fazia sucesso com o público. O mesmo não acontecia com os censores, que geralmente cortavam diversas cenas suas, quando não proibiam seus filmes inteiros. O mais interessante, todavia, é, ao se ler os relatos dos censores, perceber sua repulsa com as cenas de tortura. Curiosamente, um Estado que torturava aqueles que se punham contra ele era o mesmo que se preocupava com a representação violenta de um monstro torturador, mesmo com as obras de José Mojica Marins não tendo um intuito de crítica ao regime ou denúncia de um Estado de Exceção. Nota-se aí então uma preocupação real em encobrir os crimes de um sádico, mesmo que ele não remeta diretamente ao governo militar. LacoueLabarthe (2012), ao caracterizar o horror ocidental presente no livro O Coração das Trevas, de Joseph Conrad, aponta que ele se dá justamente nessa tentativa do ocidente de esconder toda a sua barbárie colonizadora (ou, como no caso do Zé do Caixão, de censurar suas cenas de sadismo). O horror se dá ao se tentar esconder o horror, num processo interminável, nos pontos em branco, os quais não sabemos muito bem o que aconteceu. Subvertendo essa lógica, as Trouxas interpelam justamente por serem os desvelamento momentâneo de um sistema violento que pretendia se mostrar estável através de um crescimento econômico. Os objetos de Barrio funcionam assim como a abertura de uma fresta pela qual podemos examinar as entranhas de um mecanismo roto. Como Rivera $(2008$, p. 77 ) bem aponta, "em vez de uma imagem-muro, capaz de recobrir esse terror tão íntimo, temos com Barrio imagens-furo, capazes de quase furar nossos olhos, como fez Édipo, ou de arrancá-los de suas órbitas. Imagens desastrosas". O ponto espaço/temporal é vital então, justamente por carregar a característica de levar a obra de arte (que não se apresenta como obra de arte, mas como susto) ao espectador que não está no local para ver uma obra (está ali de passagem, quando é tomado pelo choque de se deparar com um corpo). Os espectadores se sentem então como testemunhas reais de crimes recém descobertos. Mas quem teria feito tais crimes? Quem teria tentado em vão encobrir tais cadáveres que insistiram em se mostrar diante de todos? Isso só pode ser obra de um monstro abominável, um ser oculto mas também sempre presente.

Como Carroll (1999) destaca, um dos pontos para se colocar uma obra como sendo pertencente ao horror é ter um monstro que, ao mesmo tempo, represente perigo e que desafie as convenções de R. Inter. Interdisc. Art\&Sensorium, Curitiba, v.7, n.2, p. 001 - 014 Jul.- Dez. 2020 
ordem. Como uma falha ontológica, ele causa a repulsa e medo tanto nos espectadores quanto nos envolvidos na narrativa. Foucault (2001) demonstrou que, historicamente, esse monstro se fortaleceu como potência política, como a demonstração de como um monarca tirano tinha contornos de criatura antropofágica. Como já apontado, as Trouxas Ensanguentadas funcionavam então pela lógica do desvelamento. Esse desvelamento nos leva diretamente, como num silogismo, ao monstro oculto, que produziu tal atrocidade. Na obra de Barrio, o monstro não está manifesto diretamente na narrativa, mas sua aura pesa numa espécie de contracampo. Do mesmo modo, as Trouxas são como reminiscências das atrocidades que esse monstro produziu, são o testemunho da ordem que ele desvirtuou.

Se quisermos pensar numa narrativa literária ou cinematográfica de horror, podemos fazer um simples exercício, estabelecendo dois atos. Primeiro: um homem anda pelo parque com tranquilidade. Segundo: ele é interpelado por várias trouxas de sangue, que parecem ser cadáveres. Essas trouxas representam diretamente o monstro que as produziu, elas carregam em si esta aura da qual não podem se desvencilhar. Imagine você passar por essa situação, qual não seria seu espanto diante de tal atrocidade. Do mesmo modo, o monstro aqui está presente virtualmente, no imaginário. Ele é evocado a cada vez que se olha para uma trouxa e se percebe a violência que ela carrega, a impotência e fragilidade do corpo diante do monstro.

Curiosamente, há aqui uma mistura entre os monstros descritos por Foucault (2001) no campo político. Ao mesmo tempo que esse monstro é o do monarca, o dono do poder que abusa de suas vítimas justamente por ter o poder, seu modo de operar é o do monstro debaixo. Ele não conserva o gesto delicado de um monarca, que ataca sem deixar muitas marcas, como um Nosferatu. Pelo contrário, ele é um monstro vil que despedaça corpos, ele desce ao lado mais animalesco daquilo que sequer podemos chamar de humanidade. As Trouxas surgem do esgoto, estão empapadas em lama e cobertas pelo lixo, indicando sua morada. Esse monstro então se encaixa também muito bem na proposta de Carroll (1999), ele causa medo, mas acima de tudo, é repugnante.

Nesse aspecto, a Ditadura era monstruosa justamente por sua negação do Contrato Social, pelo Estado de Exceção e a negação da ordem/lei. Qual não era o desespero daqueles afligidos por tais monstros nas narrativas da vida real dos porões do DOPS? Dos indigentes perseguidos pelo Esquadrão da Morte? As Trouxas guardam não apenas os restos das vítimas, sua carne e sangue, mas carregam também a reminiscência da presença do monstro. 


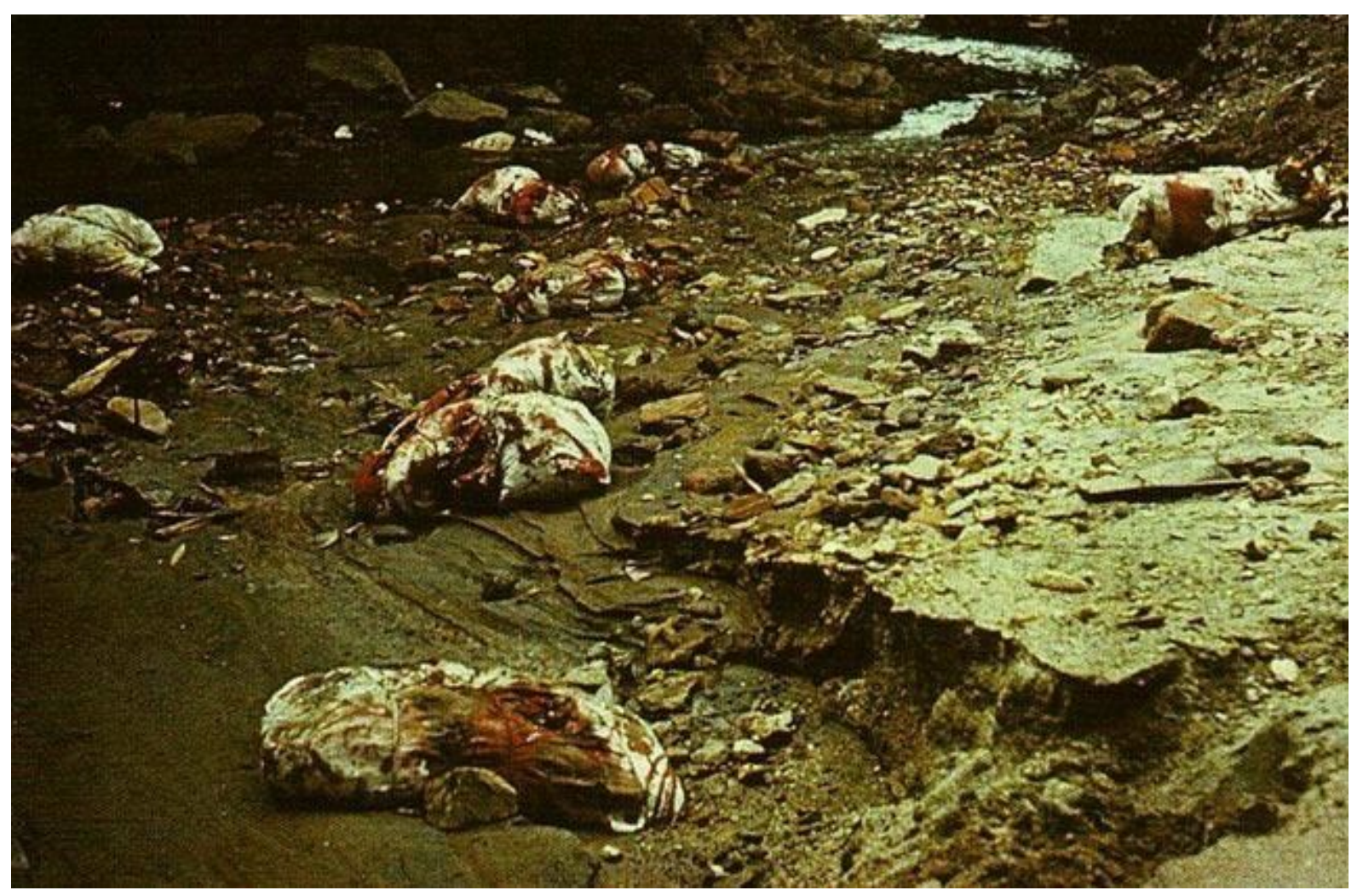

Figura 3 - As Trouxas Ensanguentadas, de Artur Barrio. Foto: César Carneiro

\section{Considerações Finais}

Procurei aqui traçar algumas características do gênero horror, as quais geralmente são utilizadas para se analisar narrativas literárias e cinematográficas. Essas características são aplicáveis também ao campo das artes plásticas e, a meu ver, ao trabalho de Artur Barrio com as Trouxas Ensanguentadas. Em períodos de Estado de Exceção, as narrativas de gênero podem servir como crítica a regimes autoritários, não apenas como entretenimento de massa. Trabalhando com o desvio (curiosamente o tema da mostra Do Corpo à Terra, na qual aconteceu a Situação T/T,1) essas obras geralmente remetem a conceitos extra-narrativos. Essa passagem do horror natural ao horror artístico é uma marca bastante frequente em diversas obras, incluindo nessa esteira, a meu ver, as Trouxas Ensanguentadas.

Como busquei demonstrar, as Trouxas podem ser vistas sob o prisma do horror artístico pela sua forma, as reações que causaram nos espectadores e naqueles envolvidos em sua narrativa e pela presença de um monstro, nesse caso invisível. Elas remetem a personagens anteriores a elas, externos à obra, as vítimas da ditadura e seus algozes. Esses objetos funcionam então como narrativas do horror, carregando todos os seus significados. Em catorze trouxas contendo detritos Barrio incorporou o horror de uma nação inteira, materializou todo um imaginário de sangue e lixo. Como na anedota sobre o Guernica, se um dos agentes do Esquadrão da Morte perguntasse a Barrio se foi ele quem produziu tal obra asquerosa, certamente ele responderia, "não fui eu, foram vocês!" 


\section{Referências Bibliográficas}

BENJAMIN, Walter. O anjo da história. 2. ed. Belo Horizonte, MG: Autêntica Editora, 2012.

CÁNEPA, Laura Loguercio. Medo de quê? uma história do horror nos filmes brasileiros. 2008, 498 p. Tese (Doutorado em Multimeios) - Programa de Pós-Graduação em Multimeios do Instituto de Artes da UNICAMP.

CALIRMAN, Cláudia. Arte brasileira na ditadura militar. 1. ed. Rio de Janeiro, RJ: Réptil Editora, 2013.

CLARK, Stuart. Pensando com demônios: a idéia de bruxaria no princípio da europa moderna. 1. ed. São Paulo, SP: Editora da Universidade de São Paulo, 2006.

CARROLL, Noël. A filosofia do horror ou paradoxo do coração. 1. ed. Campinas, SP: Papirus Editora, 1999.

DIDI-HUBERMAN, Georges. O que vemos, o que nos olha. 2. ed. São Paulo, SP: Editora 34, 2010. DOUGLAS, Mary. Pureza e perigo. 2. ed. São Paulo, SP: Perspectiva, 2014.

FOUCAULT, Michel. Os anormais: curso no collège de france (1974-1975). 1. ed. São Paulo, SP: Martins Fontes, 2001.

FREIRE, Cristina. O presente-ausente da arte dos anos 70. In: Vários autores. Anos 70: Trajetórias. 1. ed. São Paulo, SP: Iluminuras, 2005.

FREITAS, Artur. Arte de guerrilha: vanguarda e conceitualismo no brasil. 1. ed. São Paulo, SP: Editora da Universidade de São Paulo, 2013.

GAGNEBIN, Jeanne Marie. Palavras para Hurbinek. In: NESTROVSKI, Arthur; SELIGMANNSILVA, Márcio (orgs.). Catástrofe e representação. 1. ed. São Paulo, SP: Escuta, 2000. P. 99-110.

LACOUE-LABARTHE, Philippe. O horror ocidental. In: Alea: Estudos Neolatinos, vol.14 $\mathrm{n}^{\mathrm{o}} .2$, Rio de Janeiro jul./dez. 2012. P. 327-337.

RIVERA, Tania. O outro e a violência da cultura. In: Ide: psicanálise e cultura, vol. $31, n^{\circ} .47$, São Paulo. 2008. P. 75-78.

SCHILLER, Friedrich. Do sublime ao trágico. 1. ed. Belo Horizonte, MG: Autêntica Editora, 2011. 